\title{
Serum $\alpha$ - and $\gamma$-tocopherol concentrations and risk of advanced beta cell autoimmunity in children with HLA-conferred susceptibility to type 1 diabetes mellitus
}

\author{
L. Uusitalo • J. Nevalainen • S. Niinistö • G. Alfthan • \\ J. Sundvall • T. Korhonen • M. G. Kenward • H. Oja • \\ R. Veijola • O. Simell • J. Ilonen • M. Knip • \\ S. M. Virtanen
}

Received: 1 November 2007 / Accepted: 21 January 2008 / Published online: 4 March 2008

(C) Springer-Verlag 2008

\begin{abstract}
Aims/hypothesis The aim of our study was to assess the associations of serum $\alpha$ - and $\gamma$-tocopherol concentrations with the risk of advanced beta cell autoimmunity in children with HLA-conferred genetic susceptibility to type 1 diabetes mellitus.

Methods A case-control study with 108 cases with advanced beta cell autoimmunity and 216 matched control participants nested within the birth cohort of the Type 1
\end{abstract}

L. Uusitalo $\cdot$ J. Nevalainen $\cdot$ H. Oja $\cdot$ S. M. Virtanen

Tampere School of Public Health, University of Tampere,

Tampere, Finland

L. Uusitalo $(\bowtie) \cdot J$. Nevalainen $\cdot$ T. Korhonen $\cdot$ S. M. Virtanen

Department of Health Promotion and Chronic Disease Prevention,

National Public Health Institute,

Mannerheimintie 166,

00300 Helsinki, Finland

e-mail: liisa.uusitalo@uta.fi

S. Niinistö

Department of Public Health, University of Helsinki,

Helsinki, Finland

G. Alfthan · J. Sundvall

Department of Health and Functional Capacity,

National Public Health Institute,

Helsinki, Finland

M. G. Kenward

Department of Epidemiology and Population Health,

Medical Statistics Unit,

London School of Hygiene and Tropical Medicine,

London, UK

R. Veijola

The Department of Pediatrics, University of Oulu,

Oulu, Finland
Diabetes Prediction and Prevention Project. A serum sample for vitamin $\mathrm{E}$ analyses was collected from all the children in the cohort at the age of 1 year and thereafter at 12 month intervals. For each case-control group, all the repeated serum samples up to the age of seroconversion to autoantibody positivity in the case were analysed. A conditional logistic regression model was used to determine potential associations between seroconversion and serum tocopherol concentrations.

O. Simell

Department of Pediatrics, University of Turku,

Turku, Finland

O. Simell $\cdot$ M. Knip

The Juvenile Diabetes Research Foundation Center

for Prevention of Type 1 Diabetes in Finland,

Turku, Oulu and Tampere, Finland

J. Ilonen

Department of Clinical Microbiology, University of Kuopio,

Kuopio, Finland

J. Ilonen

Immunogenetics Laboratory, University of Turku,

Turku, Finland

M. Knip

Department of Pediatrics, Tampere University Hospital,

Tampere, Finland

M. Knip

Hospital for Children and Adolescents, University of Helsinki,

Helsinki, Finland

S. M. Virtanen

Tampere University Hospital Research Unit,

Tampere, Finland 
Results Serum $\alpha$ - or $\gamma$-tocopherol concentrations were not significantly associated with the risk of advanced beta cell autoimmunity. The odds ratio $(95 \% \mathrm{CI})$ for $\mu \mathrm{mol} / 1$ increase in serum concentration of the first-year sample was 0.97 $(0.92-1.03)$ for $\alpha$-tocopherol and $1.10(0.70-1.74)$ for $\gamma$-tocopherol. However, there was an interaction between high values of $\gamma$-tocopherol at the age of 1 year and the time of seroconversion $(p=0.024)$.

Conclusions/interpretation It seems unlikely that high concentrations of $\alpha$ - or $\gamma$-tocopherol protect against advanced beta cell autoimmunity in young children.

Keywords Aetiology · Beta cell autoimmunity · Children . Cholesterol $\cdot \alpha$-Tocopherol $\cdot \gamma$-Tocopherol .

Type 1 diabetes $\cdot$ Vitamin $\mathrm{E}$

$\begin{array}{ll}\text { Abbreviations } \\ \text { DIPP } & \begin{array}{l}\text { Type 1 Diabetes Prediction and Prevention } \\ \text { Project }\end{array} \\ \text { GADA } & \begin{array}{l}65 \mathrm{kDa} \text { isoform of glutamic acid } \\ \text { decarboxylase antibodies }\end{array} \\ \text { IAA } & \begin{array}{l}\text { insulin autoantibodies } \\ \text { tyrosine phosphatase-related islet antigen } 2 \\ \text { IA-2A }\end{array} \\ \text { ICA } & \text { islet cell antibodies }\end{array}$

\section{Introduction}

Vitamin E is a fat-soluble vitamin of plant origin consisting of eight structurally related compounds and is a classic free radical scavenging antioxidant [1]. The principal vitamers both in the diet and in human tissues are $\alpha$ - and $\gamma$ tocopherol [2]. Research has focused mainly on $\alpha$-tocopherol because of its superior vitamin activity in rat fetal resorption assays [3] and prevalence in the human body [1]. However, $\gamma$-tocopherol provides different antioxidant activities [2], even exceeding those of $\alpha$-tocopherol in some aspects [3, 4], and has anti-inflammatory properties beyond its antioxidant action [3]. $\gamma$-Tocopherol also seems to be a more predictive protective factor for certain types of cancer and myocardial infarction [1] than $\alpha$-tocopherol.

Free radicals have been implicated in the aetiology of type 1 diabetes mellitus. Pancreatic islet cells are especially susceptible to the toxic effects of free radicals [5]. In insulitis leading to beta cell destruction, islet-infiltrating macrophages release free radicals, and also beta cell toxic cytokines and cytotoxic $\mathrm{T}$ cells may act via excessive formation of oxygen free radicals $[6,7]$. Animal models of type 1 diabetes mellitus have indicated that vitamin $\mathrm{E}$ may have protective effects $[5,8-10]$.

Two epidemiological studies have been published on the associations of vitamin $\mathrm{E}$ with the risk of type 1 diabetes mellitus, both from Finland. The number of cases was small in both studies, but the results supported the hypothesis of vitamin $\mathrm{E}$ playing a protective role against diabetes. Serum $\alpha$-tocopherol concentrations were inversely associated with diabetes in a case-control study nested within a 21 year follow-up of adult men [11]. In a cohort of initially non-diabetic siblings of children with diabetes, we found an inverse relationship of borderline significance between serum $\alpha$-tocopherol concentrations and the risk of diabetes [12]. To the best of our knowledge, there are no epidemiological analyses of serum $\gamma$-tocopherol in this context.

In the present study, we assessed the associations of serum $\alpha$ - and $\gamma$-tocopherol concentrations with the risk of advanced beta cell autoimmunity in a birth cohort of children with HLA-conferred susceptibility to type 1 diabetes mellitus.

\section{Methods}

Participants In the Type 1 Diabetes Prediction and Prevention (DIPP) Project, a prospective population-based cohort study [13], newborn infants from the areas of three university hospitals in Finland were screened for $H L A$ $D Q B 1$-conferred susceptibility to type 1 diabetes mellitus using samples of cord blood. Infants carrying increased genetic susceptibility $\left(H L A-D Q B 1^{*} 02 / 0302\right.$ heterozygous and $D Q B 1^{*} 0302 / x$-positive individuals, $x$ standing for homozygosity or a neutral allele) were monitored for diabetes-associated autoantibodies, growth, viral infections and nutrition at 3-12 month intervals. The procedures were approved by the local Ethics Committees. The families signed informed written consent. The cases and control participants in the present analyses came from a cohort of the at-risk children born between 1 October 1996 and 1 July 2004 in Oulu University Hospital and between 20 October 1997 and 6 July 2004 in Tampere University Hospital $(n=$ $5,787,76 \%$ of the children invited).

Of the four type 1 diabetes-associated autoantibodies analysed, islet cell antibodies (ICA) were used as the primary screening tool for beta cell autoimmunity. When a child seroconverted to positivity for ICA for the first time, all the child's preceding and subsequent samples were analysed for insulin autoantibodies (IAA), $65 \mathrm{kDa}$ isoform of glutamic acid decarboxylase antibodies (GADA) and tyrosine phosphatase-related islet antigen 2 antibodies (IA2A). For the present analyses, autoantibodies were followed until 30 September 2004. Among the 5,787 children, 119 $(2.1 \%)$ were repeatedly positive for ICA plus at least one other antibody during the median follow-up time of 2.1 years (range 0.18-7.9 years) since birth. By 20 November 2004, 45 children $(0.8 \%)$ had progressed to clinical type 1 diabetes mellitus at a median age of 3.1 years 
(range 1.0-6.4 years). Among these, 36 had been repeatedly positive for ICA plus at least one other autoantibody. However, six of the remaining nine children had had one or more autoantibodies in a single sample before or at the time of diagnosis. The three persistently seronegative children had had the last blood sample drawn 1.9, 3.3 and 5.2 years before the diagnosis of diabetes, respectively. Therefore we decided to include clinical type 1 diabetes mellitus in the autoantibody endpoint. This resulted in 128 children $(2.2 \%$ of all children) with the composite endpoint of clinical diabetes or being repeatedly positive for ICA plus at least one other antibody, i.e. having advanced beta cell autoimmunity, which term will be used throughout the text for the endpoint.

The study was designed as a nested case-control study. For each case, two matched control participants were selected. First, all possible control participants who fulfilled the matching criteria were selected from the entire DIPP Nutrition cohort. The matching criteria included birth date within 3 months, the same sex, the same hospital of birth, the same genotype ( $H L A-D Q B 1^{*} 02 / 0302$ heterozygous, defined as high risk or $D Q B 1 * 0302 / x$, defined as moderate risk), and the control participants must not come from the same family as the case. The control participants could come from the same family. The control participant children must have been observed at the visit when the case turns out to be a case and they must have been seronegative and non-diabetic up to that point. From the series of all possible control participant children fulfilling the matching criteria, two control participants were randomly selected. If the selected control participants did not have a blood sample for vitamin E analysis, extra control participants were randomly selected. The control participants of each case were selected totally independently, so that the same individual could be a control for more than one case, and an individual who was already a control for one or more cases could him- or herself become a case at a later time point.

A serum sample for vitamin E analyses, separate from the sample drawn for the autoantibody follow-up, was collected from all the children in the cohort at the age of 1 year and thereafter at 12 month intervals. For each casecontrol group, all the repeated serum samples up to the age of seroconversion of the case were analysed. There were 20 cases with no vitamin E samples drawn until the age of seroconversion. These cases and their matched control participants were dropped from the analyses.

Genetic methods The $H L A-D Q B 1$ alleles were analysed as described earlier [14]. In brief, a part of the second exon of the $H L A-D Q B 1$ gene was amplified using a primer pair with a biotinylated $3^{\prime}$ primer. The biotinylated PCR products were then transferred to streptavidin-coated micro- titration plates, denatured and hybridised with sequencespecific probes labelled with lanthanide chelates: europium, terbium or samarium. Two hybridisation mixtures were used, one containing probes hybridising with $D Q B 1^{*} 0602$ and *0603, $D Q B 1 * 0603$ and *0604 and a consensus sequence, and the other containing probes specific to the $D Q B 1 * 02, * 0301$ and $* 0302$ alleles. After appropriate incubations and washings, the specific hybridisation products were detected using three-colour time-resolved fluorescence of the lanthanide chelates.

Immunological methods The detection of type 1 diabetesassociated autoantibodies has been described previously [15]. In brief, ICA were quantified by a standard indirect immunofluorescence method on sections of frozen human pancreas from a blood group O donor [16]. Serum IAA were quantified with a microassay $[17,18]$ and GADA and IA-2A with specific radiobinding assays [19, 20]. Transplacentally transferred autoantibodies, which were present in cord blood and thereafter disappeared from the child's serum [21], were excluded from the analyses.

Determination of vitamin $E$ and cholesterol Non-fasting blood samples for vitamin $\mathrm{E}$ and cholesterol analyses were collected by venipuncture. Samples were protected from light during processing. They were kept at room temperature for 30-60 min to clot. After centrifugation, a sample of at least $1 \mathrm{ml}$ serum from 1 -year-old children and $2 \mathrm{ml}$ from age 2 years onwards was separated and stored at $-70^{\circ} \mathrm{C}$ prior to analyses. Samples were transported on dry ice to the National Public Health Institute for the analyses. Serum $\alpha$ - and $\gamma$-tocopherol concentrations were measured at the Biomarker Laboratory with a micromethod on $50 \mu \mathrm{l}$ aliquots with reversed-phase HPLC with detection by fluorescence at 292/324 $\mathrm{nm}$ [22]. The precision between series was $5.0 \mathrm{CV} \%$ for $\alpha$-tocopherol and $6.7 \mathrm{CV} \%$ for $\gamma$-tocopherol. Serum cholesterol concentrations were analysed manually at the Laboratory of Analytical Biochemistry by an Olli-C photometer (Thermo Fisher Scientific Oy, Vantaa, Finland) using an enzymatic (CHOD-PAP) method. The laboratory personnel were unaware of the case-control status of the samples. Each case-control group was analysed in the same batch. Within each case-control group, the samples were in random order in relation to the case-control status.

Collection of background characteristics Information on parental age and education was registered by a structured questionnaire after the delivery. Information on gestational age, number of earlier deliveries of the mother (parity) and maternal smoking during pregnancy was received from the Medical Birth Registries of the Oulu and Tampere University Hospitals. 
Statistical methods The study endpoint is interval-censored. Therefore, a conditional likelihood analysis of a logistic regression model was used within the nested case-control design to estimate potential associations between seroconversion and serum $\alpha$-tocopherol and $\gamma$-tocopherol levels. The explanatory variables were treated as both continuous and categorical after aggregation into low (values less than the 25 th percentile), intermediate (within the interquartile range) and high (above the 75th percentile) values. As more than $40 \%$ of the seroconversions took place before the second year of age, the first-year serum values were employed in the model. A model that allowed an interaction with the time of seroconversion was fitted as well.
Moreover, the effect of an average category of individual $\alpha$-tocopherol and $\gamma$-tocopherol concentrations over time on the response was estimated. Adjusted multiple logistic regression models included serum cholesterol and background characteristics (education of the mother and the father, maternal age, duration of gestation, diabetes of a firstdegree relative, number of earlier deliveries, maternal smoking during pregnancy) in addition to $\alpha$ - or $\gamma$-tocopherol concentrations. The analyses were conducted on the observed data and, to reduce potential bias associated with missing explanatory variables and to allow individuals with incomplete sets of explanatory variables to be included, multiple imputation was used. The sequential imputation regression
Table 1 Characteristics of cases with advanced beta cell autoimmunity and two seronegative control participants per case matched individually for genetic risk group, delivery hospital, sex and birth date ( \pm 3 months)
${ }^{a}$ Eight individuals were control participants for two cases, and are counted only once. One control participant became a case at a later time point, and is counted as a case

${ }^{\mathrm{b}} x$ not equal to $* 02, * 0301$, *0602

${ }^{\mathrm{c}}$ At the time of the birth of the child

\begin{tabular}{|c|c|c|}
\hline & Cases, $n(\%)$ & Control participants, $n(\%)$ \\
\hline$n$ & 108 & $207^{\mathrm{a}}$ \\
\hline Boys & $67(62.0)$ & $129(62.3)$ \\
\hline Girls & $41(38.0)$ & $78(37.7)$ \\
\hline \multicolumn{3}{|l|}{ Delivery hospital } \\
\hline Oulu & $53(49.1)$ & $101(48.8)$ \\
\hline Tampere & $55(50.9)$ & $106(51.2)$ \\
\hline \multicolumn{3}{|l|}{ Genetic risk group } \\
\hline High risk $(D Q B 1 * 02 / * 0302)$ & $34(31.5)$ & $63(30.4)$ \\
\hline Moderate risk $\left(D Q B 1^{*} 0302 / x\right)^{\mathrm{b}}$ & $74(68.5)$ & $144(69.6)$ \\
\hline \multicolumn{3}{|l|}{ Familial diabetes } \\
\hline Yes & $16(14.8)$ & $11(5.3)$ \\
\hline No & $88(81.5)$ & $186(89.9)$ \\
\hline Missing information & $4(3.7)$ & $10(4.8)$ \\
\hline \multicolumn{3}{|l|}{ Maternal age (years) ${ }^{\mathrm{c}}$} \\
\hline$<25$ & $21(19.4)$ & $34(16.4)$ \\
\hline $25-30$ & $34(31.5)$ & $73(35.3)$ \\
\hline $30-35$ & $24(22.2)$ & $66(31.2)$ \\
\hline$>35$ & $29(26.9)$ & $34(16.4)$ \\
\hline \multicolumn{3}{|l|}{ Number of earlier deliveries by the mother ${ }^{c}$} \\
\hline 0 & $39(36.1)$ & $91(44.0)$ \\
\hline 1 & $42(38.9)$ & $58(28.0)$ \\
\hline 2 & $15(13.9)$ & $36(17.4)$ \\
\hline$\geq 3$ & $12(11.1)$ & $22(10.6)$ \\
\hline \multicolumn{3}{|l|}{ Maternal vocational education $^{\mathrm{c}}$} \\
\hline Academic & $28(25.9)$ & $33(15.9)$ \\
\hline Upper secondary vocational education & $33(30.6)$ & $104(50.2)$ \\
\hline Vocational school or course & $34(31.5)$ & $55(26.6)$ \\
\hline None & $10(9.3)$ & $7(3.4)$ \\
\hline Missing information & $3(2.8)$ & $8(3.9)$ \\
\hline \multicolumn{3}{|l|}{ Paternal vocational education ${ }^{c}$} \\
\hline Academic & $24(22.2)$ & $44(21.3)$ \\
\hline Upper secondary vocational education & $36(33.3)$ & $67(32.4)$ \\
\hline Vocational school or course & $39(36.1)$ & $77(37.2)$ \\
\hline None & $6(5.6)$ & $7(3.4)$ \\
\hline Missing information & $3(2.8)$ & $12(5.8)$ \\
\hline \multicolumn{3}{|l|}{ Maternal smoking during pregnancy } \\
\hline Yes & $8(7.4)$ & $14(6.8)$ \\
\hline No & $96(88.9)$ & $185(89.4)$ \\
\hline Missing information & $4(3.7)$ & $8(3.9)$ \\
\hline Mean gestational age (weeks) & 39.3 & 39.7 \\
\hline Missing information & $2(1.9)$ & $3(1.5)$ \\
\hline
\end{tabular}


method [23] as implemented in the IVEware software was used to generate five sets of imputed missing values and the final estimates and their SEs were calculated according to Rubin's rules [24]. $\alpha$-Tocopherol and $\gamma$-tocopherol concentrations were imputed for 11 cases and 17 control participants. SAS version 9.1.3 (SAS Institute, Cary, NC, USA) was used in the analyses. Full details of the imputation models used are available from the authors on request.

\section{Results}

The distributions of sex, delivery hospital and genetic risk group, which were used as matching criteria, were identical for cases and control participants (Table 1). Diabetes in a first-degree relative was more common among cases than control participants. The mothers of the cases belonged to the highest age and education categories more frequently than the mothers of control participant children. There were one twin pair and three sibling pairs among the study population. There were no siblings within the same casecontrol group. Neither child of the twin pair was a case.

The age-specific mean concentrations of control participants ranged from 15.5 to $18.5 \mu \mathrm{mol} / 1$ for $\alpha$-tocopherol, from 1.18 to $2.09 \mu \mathrm{mol} / \mathrm{l}$ for $\gamma$-tocopherol and from 4.39 to $4.88 \mathrm{mmol} / 1$ for cholesterol (Fig. 1). Concentrations of $\alpha$-tocopherol and cholesterol were stable across the age range of 1-6 years, while the $\gamma$-tocopherol concentration at the age of 1 year tended to be lower than in the older age groups.

Serum $\alpha$ - or $\gamma$-tocopherol concentrations were not significantly associated with the risk of advanced beta cell autoimmunity (Table 2). $\alpha$-Tocopherol or $\gamma$-tocopherol concentrations at the age of 1 year were not significant predictors of seroconversion, irrespective of whether they were analysed as continuous or categorical quartile variables.
Neither were the average levels of $\alpha$ - or $\gamma$-tocopherol in all samples up to the time of seroconversion associated with the risk. Multiple imputation of missing values or adjustment for serum cholesterol concentration, education of the mother and the father, maternal age, duration of gestation, diabetes in a first-degree relative, number of earlier deliveries and maternal smoking during pregnancy did not change the magnitude of the associations or improve the precision of the results.

However, there was an interaction between high vs intermediate values of $\gamma$-tocopherol at the age of 1 year and the time of seroconversion (Fig. 2), possibly indicating an inverse association between $\gamma$-tocopherol and the risk of advanced beta cell autoimmunity at a young age $(p=0.024)$. $\alpha$-Tocopherol concentration at the age of 1 year analysed as a continuous variable showed a borderline interaction with the time of seroconversion $(p=0.094)$.

\section{Discussion}

In the present case-control study nested within a birth cohort of children with HLA-conferred susceptibility to type 1 diabetes mellitus, serum $\alpha$ - or $\gamma$-tocopherol concentrations were not significantly associated with the risk of advanced beta cell autoimmunity. Potential confounding by several sociodemographic and clinical variables was controlled for by matching or adding them into the statistical models as covariates. The only significant finding was an interaction of high $\gamma$ tocopherol concentrations at the age of 1 year with the time to seroconversion. In the light of these results, a substantial protective effect of high $\alpha$ - or $\gamma$-tocopherol concentrations against pre-type 1 diabetes in young children seems unlikely.

In a small cross-sectional study, plasma $\alpha$-tocopherol concentrations of individuals with type 1 diabetes-associated
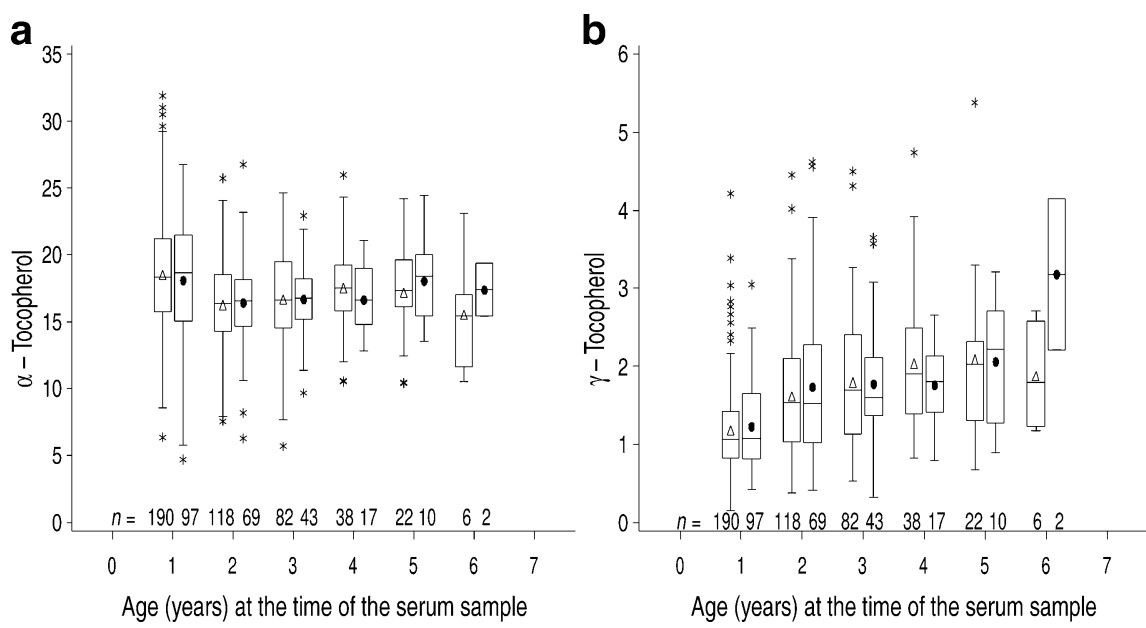

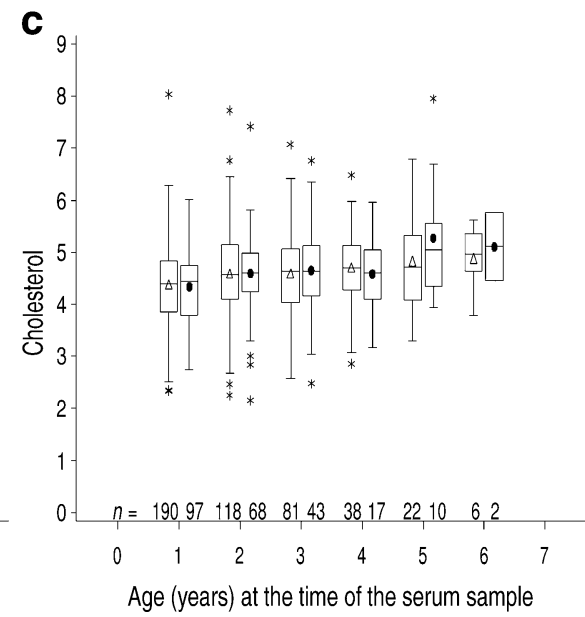

Fig. 1 Serum $\alpha$-tocopherol $(\mu \mathrm{mol} / 1)(\mathbf{a}), \gamma$-tocopherol $(\mu \mathrm{mol} / \mathrm{l})(\mathbf{b})$ and cholesterol $(\mathrm{mmol} / \mathrm{l})(\mathbf{c})$ concentrations of control participants (triangles, mean values) and cases (circles, mean values) by age groups. The central bar in the boxplots represents the median concentration, the box represents the interquartile range (IQR), and the whiskers represent the smallest and largest non-outlier concentrations. The asterisks represent outliers, i.e. observations that lie more than $1.5 \times$ IQR lower than the first quartile or $1.5 \times$ IQR higher than the third quartile 
Table 2 Associations of serum $\alpha$ - and $\gamma$-tocopherol concentrations with the risk of advanced beta cell autoimmunity in conditional logistic regression models

\begin{tabular}{|c|c|c|c|c|c|}
\hline & No. of cases & $\begin{array}{l}\text { No. of control } \\
\text { participants }\end{array}$ & Odds ratio & $95 \% \mathrm{CI}$ & $p$ value \\
\hline Per $1 \mu \mathrm{mol} / 1$ increase in $\alpha$-tocopherol ${ }^{\mathrm{a}}$ & 97 & 199 & 0.97 & $0.92-1.03$ & 0.40 \\
\hline Early values of $\alpha$-tocopherol ${ }^{\mathrm{b}}$ & 97 & 199 & & & \\
\hline Low & 28 & 46 & 1.51 & $0.81-2.81$ & 0.19 \\
\hline Intermediate $^{c}$ & 43 & 105 & 1.00 & - & \\
\hline High & 26 & 48 & 1.29 & $0.70-2.36$ & 0.42 \\
\hline Overall values of $\alpha$-tocopherol ${ }^{\mathrm{d}}$ & 108 & 216 & & & \\
\hline Low & 30 & 52 & 1.18 & $0.63-2.20$ & 0.61 \\
\hline Intermediate $^{c}$ & 55 & 108 & 1.00 & - & \\
\hline High & 23 & 56 & 0.80 & $0.44-1.47$ & 0.48 \\
\hline Per $1 \mu \mathrm{mol} / 1$ increase in $\gamma$-tocopherol ${ }^{\mathrm{a}}$ & 97 & 199 & 1.10 & $0.70-1.74$ & 0.67 \\
\hline Early values of $\gamma$-tocopherol ${ }^{\mathrm{b}}$ & 97 & 199 & & & \\
\hline Low & 25 & 49 & 1.23 & $0.66-2.27$ & 0.52 \\
\hline Intermediate $^{c}$ & 44 & 104 & 1.00 & - & \\
\hline High & 28 & 46 & 1.35 & $0.75-2.41$ & 0.31 \\
\hline Overall values of $\gamma$-tocopherol ${ }^{\mathrm{d}}$ & 108 & 216 & & & \\
\hline Low & 27 & 53 & 1.05 & $0.58-1.90$ & 0.87 \\
\hline Intermediate $^{c}$ & 53 & 109 & 1.00 & - & \\
\hline High & 28 & 54 & 1.07 & $0.61-1.87$ & 0.82 \\
\hline
\end{tabular}

${ }^{\text {a }}$ First-year sample

${ }^{\mathrm{b}}$ First-year sample results grouped into low ( 0 to 25 th percentile), intermediate (25th to 75 th percentile) and high (75th percentile to 100 th percentile) values

${ }^{\mathrm{c}}$ Reference group

${ }^{\mathrm{d}}$ Average grouping (low/intermediate/high) over all values up to the seroconversion

autoantibodies tended to be slightly lower than those of unaffected control participants, but the difference was not significant [25]. In two earlier cohort studies, however, a significant [11] or borderline [12] inverse association between serum $\alpha$-tocopherol concentrations and type 1 diabetes mellitus was observed. The number of diabetic cases in these studies ranged from 16 to 26. The serum samples were stored at $-20^{\circ} \mathrm{C}$ for several years, which may cause a substantial decrease in $\alpha$-tocopherol concentrations [26]; at $-70^{\circ} \mathrm{C}$, tocopherols have been shown to be stable

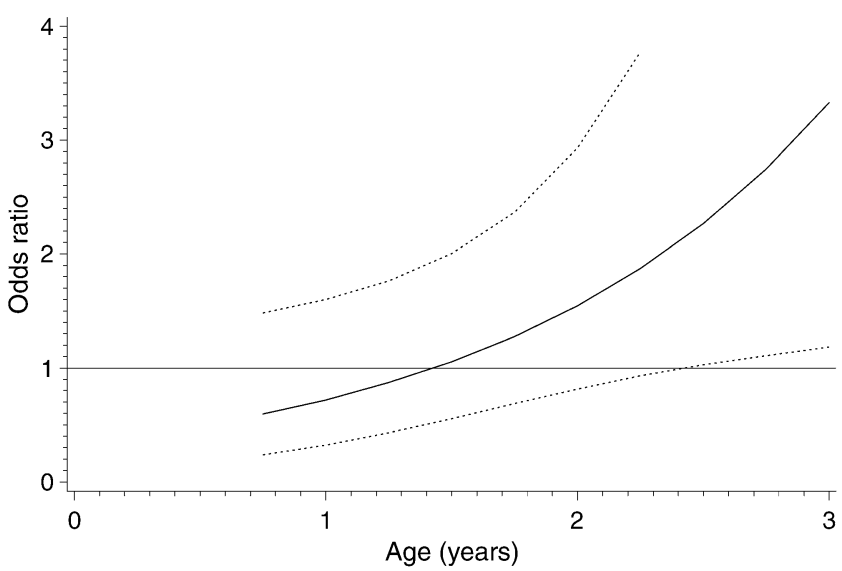

Fig. 2 Odds ratios (solid line) and 95\% CIs (dotted lines) of developing advanced beta cell autoimmunity for high vs intermediate $\gamma$-tocopherol concentrations in the first-year sample, presented by age for at least 4 years of storage [27]. Indeed, the mean $\alpha$-tocopherol concentrations were higher in the samples of the present study stored at $-70^{\circ} \mathrm{C}$ than in the earlier studies. The mean concentration of control participants was $14.9 \mu \mathrm{mol} / 1$ in one study [11], $9.22 \mu \mathrm{mol} / 1$ in another [12] and $15.5-18.5 \mu \mathrm{mol} / \mathrm{l}$ in the present study. Because of the approximately fourfold number of cases and better preserved serum samples, we consider the present results of no association more reliable than the earlier findings of an inverse association, even if one would have expected that the error caused by the degradation of $\alpha$-tocopherol during storage would have biased the association towards null. However, the rate of decline of vitamin $\mathrm{E}$ has been shown to vary considerably between individuals [26]; thus, one can not rule out the possibility that some other components in serum influence the individual rate of decrease in $\alpha$-tocopherol during storage, and are themselves associated with the risk of type 1 diabetes, causing the observed associations in the two earlier studies [12].

On the other hand, the discrepant results of the earlier cohort studies and the present study may result from differences in the study population and the endpoint variable used. In other studies $[11,12]$, the endpoint was clinical type 1 diabetes mellitus, while in the present study and in another [25] the outcome was beta cell autoimmunity, representing a prediabetic phase. It is possible that high vitamin $\mathrm{E}$ 
concentrations protect against the development of prediabetes to overt diabetes and are not as strongly associated with the emergence of autoantibodies in earlier phases of the disease process. Compatible with this view, we found a marginally significant association between serum $\alpha$-tocopherol and risk of clinical diabetes in a cohort of seropositive children [12]. Also, the effect of $\alpha$-tocopherol could differ by age group. In the present data, the study individuals were younger than in the earlier studies. In other studies, the average age of the cases was 28 years [11], 13.1 years [12] and 13.8 years [25], and 2.5 years in the present study.

There may be also methodological reasons for the lack of association between serum $\alpha$-tocopherol concentrations and prediabetes in the present study. For more than $40 \%$ of the cases there was only one vitamin E sample available. It has been shown that day-to-day intra-individual variation in plasma $\alpha$-tocopherol may cause large attenuations in the observed associations with any other factors, when a single measurement per person is used [28]. Furthermore, the validity of serum or plasma $\alpha$-tocopherol as an indicator of dietary intake is uncertain. The correlations between the concentrations and intakes of $\alpha$-tocopherol or vitamin $\mathrm{E}$ have been weak [29, 30], especially among non-users of vitamin $E$ supplements $[31,32]$. In children, most of the reported correlations have been non-significant [33-36], while in one study [37] a moderate correlation was found. However, the weak correlations could result from problems associated with the dietary assessment methods [38].

To our knowledge, this is the first epidemiological report on the association of blood $\gamma$-tocopherol concentrations and type 1 diabetes mellitus. We observed an interaction of high $\gamma$-tocopherol concentrations at the age of 1 year with the time to seroconversion. Because most of the seroconversions took place at an early age, it was not possible to separate the effect of age from the effect of time from the $\gamma$-tocopherol measurement to the seroconversion. Thus, high $\gamma$-tocopherol concentrations could be protective in the youngest children only, or they might offer only short-term protection against advanced beta cell autoimmunity. These data are compatible with the interpretation that high $\gamma$-tocopherol concentrations at the age of 1 year are associated with an increased risk of seroconversion at a later age; for biological reasons, this interpretation seems less likely. It is interesting to note that $\gamma$-tocopherol concentrations tended to be lower at the age of 1 year, co-occurring with the age of a possible protective effect provided by high concentrations.

In the light of these preliminary findings, $\gamma$-tocopherol provides an interesting target for future research. To confirm or rule out the possible inverse association of serum vitamin $\mathrm{E}$ with type 1 diabetes mellitus, studies with multiple vitamin $\mathrm{E}$ measurements per individual and still larger number of cases, preferably with clinical disease, are needed. Because of the uncertain validity of serum tocopherol concentrations as an indicator of dietary intake, studies on the association of dietary vitamin $\mathrm{E}$ intake with the development of type 1 diabetes mellitus are particularly interesting.

Acknowledgements We thank I. Salminen and H. Haponen for their skilful assistance, and the DIPP research staff for excellent collaboration. We are grateful to the families who participated in the study. Supported by Academy of Finland (grants 63672, 79685,79686, 80846, 201988, 210632), Finnish Diabetes Association, Finnish Diabetes Research Foundation, Finnish Pediatric Research Foundation, Häme Foundation of the Finnish Culture Fund, Juho Vainio Foundation, Yrjö Jahnsson Foundation, Medical Research Funds, Turku, Oulu and Tampere University Hospitals, Juvenile Diabetes Research Foundation (grants 197032, 4-1998-274, 4-1999-731, 4-2001-435), Novo Nordisk Foundation and EU Biomed 2 (BMH4-CT98-3314), Doctoral Programmes for Public Health and Jalmari and Rauha Ahokas Foundation.

Duality of interest The authors declare that there is no duality of interest associated with this manuscript

\section{References}

1. Hensley K, Benaksas EJ, Bolli R et al (2004) New perspectives on vitamin $\mathrm{E}: \gamma$-tocopherol and carboxyethylhydroxychroman metabolites in biology and medicine. Free Radic Biol Med 36:1-15

2. Wagner KH, Kamal-Eldin A, Elmadfa I (2004) Gamma-tocopherol: an underestimated vitamin. Ann Nutr Metab 48:169-188

3. Jiang Q, Christen S, Shigenaga MK, Ames BN (2001) $\gamma$-Tocopherol, the major form of vitamin $\mathrm{E}$ in the US diet, deserves more attention. Am J Clin Nutr 74:714-722

4. Dietrich M, Traber M, Jacques PF, Cross CE, Youqing H, Block G (2006) Does $\gamma$-tocopherol play a role in the primary prevention of heart disease and cancer? A review. J Am Coll Nutr 25:292-299

5. Asayama K, Kooy NW, Burr IM (1986) Effect of vitamin E deficiency and selenium deficiency on insulin secretory reserve and free radical scavenging systems in islets: decrease of islet manganosuperoxide dismutase. J Lab Clin Med 107:459-464

6. Rabinovitch A (1992) Free radicals as mediators of pancreatic islet $\beta$-cell injury in autoimmune diabetes. J Lab Clin Med 119:455-456

7. Rabinovitch A, Suarez-Pinzon WL (1998) Cytokines and their roles in pancreatic islet $\beta$-cell destruction and insulin-dependent diabetes mellitus. Biochem Pharmacol 55:1139-1149

8. Slonim AE, Surber ML, Page DL, Sharp RA, Burr IM (1983) Modification of chemically induced diabetes in rats by vitamin $\mathrm{E}$. J Clin Invest 71:1282-1288

9. Behrens WA, Scott FW, Madere R, Trick K, Hanna K (1986) Effect of dietary vitamin $\mathrm{E}$ status in the BB rat during development and after the onset of diabetes. Ann Nutr Metab 30:157-165

10. Beales PE, Williams AJ, Albertini MC, Pozzilli P (1994) Vitamin E delays diabetes onset in the non-obese diabetic mouse. Horm Metab Res 26:450-452

11. Knekt P, Reunanen A, Marniemi J, Leino A, Aromaa A (1999) Low vitamin $E$ status is a potential risk factor for insulindependent diabetes mellitus. J Intern Med 245:99-102

12. Uusitalo L, Knip M, Kenward MG et al (2005) Serum alphatocopherol concentrations and risk of type 1 diabetes mellitus: a cohort study in siblings of affected children. J Pediatr Endocrinol Metab 18:1409-1416

13. Kupila A, Muona P, Simell T et al (2001) Feasibility of genetic and immunological prediction of type 1 diabetes in a populationbased birth cohort. Diabetologia 44:290-297 
14. Ilonen J, Reijonen H, Herva E et al (1996) Rapid HLA-DQB1 genotyping for four alleles in the assessment of risk for IDDM in the Finnish population. Diabetes Care 19:795-800

15. Virtanen SM, Kenward MG, Erkkola M et al (2006) Age at introduction of new foods and advanced beta-cell autoimmunity in young children with HLA-conferred susceptibility to type 1 diabetes. Diabetologia 49:1512-1521

16. Bottazzo GF, Florin-Christensen A, Doniach D (1974) Islet cell antibodies in diabetes mellitus with autoimmune polyendocrine deficiencies. Lancet ii:1279-1282

17. Ronkainen M, Hämäläinen A-M, Koskela $\mathrm{P}$, Åkerblom HK, Knip M, the Finnish TRIGR Study Group (2001) Pregnancy induces non-immunoglobulin insulin-binding activity in both maternal and cord blood serum. Clin Exp Immunol 124: $131-136$

18. Williams AJK, Bingley PJ, Bonifacio E, Palmer JP, Gale EAM (1997) A novel micro-assay for insulin autoantibodies. J Autoimmun 10:473-478

19. Savola K, Sabbah E, Kulmala P, Vähäsalo P, Ilonen J, Knip M (1998) Autoantibodies associated with type 1 diabetes mellitus persist after diagnosis in children. Diabetologia 41:1293-1297

20. Savola K, Bonifacio E, Sabbah E et al (1998) IA-2 antibodies-a sensitive marker of IDDM with clinical onset in childhood and adolescence. Diabetologia 41:424-429

21. Hämäläinen A-M, Ronkainen MS, Åkerblom HK, Knip M, the Finnish TRIGR Study Group (2000) Postnatal elimination of transplacentally acquired disease-associated antibodies in infants born to families with type 1 diabetes. J Clin Endocrinol Metab 85:4249-4253

22. Anttolainen M, Valsta L, Alfthan G, Kleemola P, Salminen I, Tamminen M (1996) Effect of extreme fish consumption on dietary and plasma antioxidant levels and fatty acid composition. Eur J Clin Nutr 50:741-746

23. Raghunathan TE, Lepkowski JM, van Hoewyk J, Solenberger P (2001) A multivariate technique for multiply imputing missing values using a sequence of regression models. Survey Methodology 27:85-95

24. Rubin DB (1987) Multiple imputation for nonresponse in surveys. Wiley, New York

25. Leinonen JS, Alho H, Harmoinen A, Lehtimäki T, Knip M (1998) Unaltered antioxidant activity of plasma in subjects at increased risk for IDDM. Free Radic Res 29:159-164

26. Ocke MC, Schrijver J, Obermann-de Boer GL, Bloemberg BPM, Haenen GRMM, Kromhout D (1995) Stability of blood (pro) vitamins during four years of storage at $-20^{\circ} \mathrm{C}$ : consequences for epidemiologic research. J Clin Epidemiol 48:1077-1085
27. Comstock GW, Norkus EP, Hoffman SC, Xu M-W, Helzlsouer KJ (1995) Stability of ascorbic acid, carotenoids, retinol, and tocopherols in plasma stored at $-70^{\circ} \mathrm{C}$ for four years. Cancer Epidemiol Biomarkers Prev 4:505-507

28. Tangney CC, Shekelle RB, Raynor W, Gale M, Betz EP (1987) Intra- and interindividual variation in measurements of $\beta$ carotene, retinol, and tocopherols in diet and plasma. Am J Clin Nutr 45: 764-769

29. Sasaki S, Ushio F, Amano K et al (2000) Serum biomarker-based validation of a self-administered diet history questionnaire for Japanese subjects. J Nutr Sci Vitaminol (Tokyo) 46:285-296

30. Kabagambe EK, Baylin A, Allan DA, Siles X, Spiegelman D, Campos H (2001) Application of the method of triads to evaluate the performance of food frequency questionnaires and biomarkers as indicators of long-term dietary intake. Am J Epidemiol 154: $1126-1135$

31. Stryker S, Kaplan L, Stein EA, Stampfer MJ, Sober A, Willett WC (1988) The relation of diet, cigarette smoking, and alcohol consumption to plasma beta-carotene and alpha-tocopherol levels. Am J Epidemiol 127:283-296

32. McNaughton SA, Marks GC, Gaffney P, Williams G, Green A (2005) Validation of a food-frequency questionnaire assessment of carotenoid and vitamin $\mathrm{E}$ intake using weighed food records and plasma biomarkers: The method of triads model. Eur J Clin Nutr 59:211-218

33. Hercberg S, Preziosi P, Galan P et al (1994) Vitamin status of a healthy French population: Dietary intakes and biochemical markers. Int J Vitam Nutr Res 64:220-232

34. Ortega H, Castilla P, Gomez-Coronado D et al (2005) Influence of apolipoprotein $\mathrm{E}$ genotype on fat-soluble plasma antioxidants in Spanish children. Am J Clin Nutr 81:624-632

35. Drewel BT, Giraud DW, Davy SR, Driskell JA (2006) Less than adequate vitamin $\mathrm{E}$ status observed in a group of preschool boys and girls living in the United States. J Nutr Biochem 17:132-138

36. Kim Y-N, Lora KR, Giraud DW, Driskell JA (2006) Nonsupplemented children of Latino immigrants have low vitamin $\mathrm{E}$ intakes and plasma concentrations and normal vitamin $\mathrm{C}$, selenium, and carotenoid intakes and plasma concentrations. J Am Diet Assoc 106:385-391

37. Byers T, Trieber F, Gunter E et al (1993) The accuracy of parental reports of their children's intake of fruits and vegetables: validation of a food frequency questionnaire with serum levels of carotenoids and vitamins C, A, and E. Epidemiology 4:350-355

38. Romieu I, Stampfer MJ, Stryker WS et al (1990) Food predictors of plasma beta-carotene and alpha-tocopherol: validation of a food frequency questionnaire. Am J Epidemiol 131:864-876 